\title{
Effects of Human Factors on Public Use of Standing-Type Personal Mobility Vehicle
}

\author{
Naohisa Hashimoto (D), Kohji Tomita $\left(\mathbb{D}\right.$, Osamu Matsumoto $\mathbb{D}^{D}$, and Ali Boyali $(\mathbb{D}$ \\ Human Mobility Research Center, National Institute of Advanced Industrial Science and Technology, Umezono, \\ Tsukuba 305-8568, Japan \\ Correspondence should be addressed to Naohisa Hashimoto; naohisa-hashimoto@aist.go.jp
}

Received 13 May 2020; Revised 9 November 2020; Accepted 16 November 2020; Published 3 December 2020

Academic Editor: Zuduo Zheng

Copyright (c) 2020 Naohisa Hashimoto et al. This is an open access article distributed under the Creative Commons Attribution License, which permits unrestricted use, distribution, and reproduction in any medium, provided the original work is properly cited.

\begin{abstract}
To significantly reduce the occurrence of severe traffic accidents, reducing the number of vehicles in urban areas should be considered. Personal mobility is essential for realizing this reduction, which requires consideration of the last-/first-mile problem. The overall objective of our research is to solve this problem using standing-type personal mobility vehicles as transportation devices; however, to evaluate the feasibility of such vehicles as future mobility devices, it is necessary to evaluate their operation under real-world conditions. Therefore, in this study, experimental and survey data relating to the velocity, stability, safety, and comfort of a standing-type personal mobility device are obtained to evaluate its performance in three different scenarios. The results show that the personal mobility vehicle is socially well received and can be safely operated on sidewalks, irrespective of the gender or age of the driver; moreover, the results suggest that subjects who routinely use a bicycle are adept at avoiding and absorbing the impacts of small holes and bumps, thereby yielding reduced acceleration values (in all directions) and pitch, roll, and yaw rates. This is anticipated to benefit the future development of personal mobility devices and help realize effective and accessible public transport systems, as well as reduce the number of vehicles in urban areas.
\end{abstract}

\section{Introduction}

The ever-increasing population and transportation requirements of societies have led to an increase in urban traffic, congestion, and air pollution; this has detrimental effects on the quality of life of people [1-6].

A potential solution to these problems is to reduce the use of individual cars in urban areas by encouraging city dwellers to use public transport for their daily commuting necessities and personal mobility to access the nearest public transport hubs and shopping centers, as well as for other short distance journeys. In the literature, the problem of reaching the nearest transportation hub is referred to as the last-/first-mile problem [7-13].

At present, automobiles remain the optimal mode of transportation for long-range door-to-door journeys, owing to the comfort they provide. However, at least a portion of the population-though not all-could switch from using conventional automobiles to public transportation; this would help address the aforementioned traffic issues. Nevertheless, until the last-/first-mile problem is solved-in particular, for people with ambulatory needs, such as the elderly, who make up a quarter of the Japanese population [14] - the problems of increasing usage of individual transportation will persist. Considerable research efforts have been focused on using personal mobility and small electric vehicles to solve the last-/first-mile problem [9].

Solving the last-/first-mile problem is difficult when focusing on only one type of transportation because environmental conditions, legislation and regulations, users, and user preferences vary significantly around the globe. Thus, several studies have sought to solve the problem using multimodal approaches. Chen proposed a method for optimizing the location and capacity parameters of a park-andride system to solve the last-/first-mile problem [15]. Pavkova et al. proposed a method for expanding public 
transportation resources, taking the city of Melbourne, Australia, as an example [16]. Other researchers have proposed numerous alternative methods to solve these problems, including automated vehicles, car and bike sharing, and mobility-as-a-service applications [17-21].

This study focuses on personal mobility vehicles, which offer a promising solution to the last-/first-mile problem and might thereby help realize effective, accessible, and multimodal public transportation networks for urban areas. Personal mobility vehicles are defined as transportation devices for individual use $[10,11,13]$. Several vehicles (e.g., electric scooters, single-seater mobility devices, and wheelchair-type mobility devices) are considered as personal mobility vehicles. The present study focuses on the lesscommonly studied standing-type personal mobility vehicle. Pham et al. used a numerical simulation and an experiment (conducted in a controlled environment) to investigate the acceptance of pedestrians for such vehicles on sidewalks by studying their responses-in terms of personal space-when walking amongst people using standing-type personal mobility devices [13]. Lavallee investigated the safety of these vehicles and presented an analysis of the existing safety regulations for Segways (Segway, Inc., New Hampshire, USA), as well as the legal framework for their use and their traffic rules [22]. A local government review of the utilization of Segway in the Australian Capital Territory was published in 2012; it discussed the acceptance, safety, impacts, merits, and demerits of Segway use within a community [23]. Several studies have also investigated standing-type vehicles designed for use as assistive mobility devices [24-27]. At present, the empirical studies investigating real subjects using new self-balancing vehicle models in public spaces are found to lack detail. Performing experiments on public roads - to analyze public safety and determine the impacts of human factors (e.g., age, user experience, and gender)-is crucial for the introduction of new types of personal vehicle. Experimental research into these standing-type vehicles using six-dimensional sensors to quantify the effects of human factors on public roads has not been published. In particular, the use of standing-type vehicles in public areas is prohibited in Japan, and several other countries/areas also impose their own strict regulations; thus, research into the use of these devices in public areas is limited compared to other types of personal mobility vehicle.

Therefore, in this paper, we present the results of our research into standing-type personal mobility devices, focusing on the effects that human factors have upon their use. We aim to evaluate the feasibility of standing-type personal mobility vehicles as solutions to the last-/first-mile problem by conducting experiments in public areas with a mixed group of subjects and using questionnaires to gauge perceptions of the vehicles and trials. Three different experimental scenarios were prepared to evaluate various types of experimental data; furthermore, we conducted questionnaires to assess the perceptions of the subjects regarding the vehicle and trials. Thus, the objectives of this paper are as follows:
(1) To investigate the effects of these devices on the traffic flow and pedestrian and cyclist behaviors on shared roads

(2) To investigate the amenability and adaptability of different demographics-including the elderly-to several characteristics of the device

(3) To identify weaknesses in the design and improve the uptake of the general public for these devices

From these objectives, the main contribution of this paper is to prove the minimal effects on the flow of pedestrians and cyclists, which was described in objective 1, and the possible human factors on riding the Winglet, which was described in objective 2 .

In the following sections, we describe the personal mobility vehicle, experiments, and various results obtained from different sources.

\section{Personal Mobility Vehicle}

In the experiments, we used a Winglet personal mobility device, an assistive, standing-type mobility vehicle developed by the Toyota Motor Corporation of Japan; it is demonstrated in Figure $1[28,29]$.

The Winglet is lightweight, compact, and more portable than other devices such as the Segway [30]. Table 1 lists the key specifications of the Winglet. Each Winglet was equipped with several sensors (Figure 1) to record nearincident scenes and obtain the following information:

(1) Acceleration $(X, Y$, and $Z)$

(2) Yaw, roll, and pitch

(3) Yaw rate, roll rate, and pitch rate

(4) Velocity

(5) Duration of speed warning (a warning triggered when the maximum speed is reached)

(6) Trajectory

(7) Video data (for extracting information on incident and near-incident situations)

Generally, one of the most important issues in the introduction of electric vehicles is battery life, and personal mobility devices are subject to the same issue [31-33]. The charging voltage of the Winglet is $\mathrm{AC} 100 \mathrm{~V}$, which is the standard voltage in Japan. Therefore, Winglets can be charged at home and in several places in Japan. A special charger adapter, which is a DC/AC converter, is used to charge the device. Thus, it is assumed that this charger adapter can be easily replaced when the Winglet is used outside Japan. We used a dash-cam (commonly used in passenger vehicles) to record video data of the surroundings. The viewing angle was approximately $120^{\circ}$, and the number of pixels was $1 \times 108$; we considered this to be sufficient for recording, and the front and both side views could be analyzed. Moreover, distances could be verified from near contact-distance to more than $10 \mathrm{~m}$. 


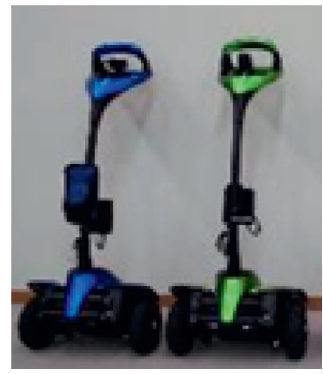

(a)

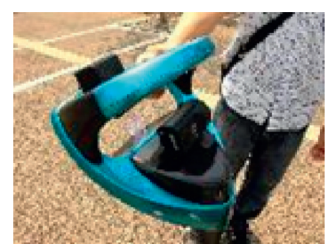

(b)

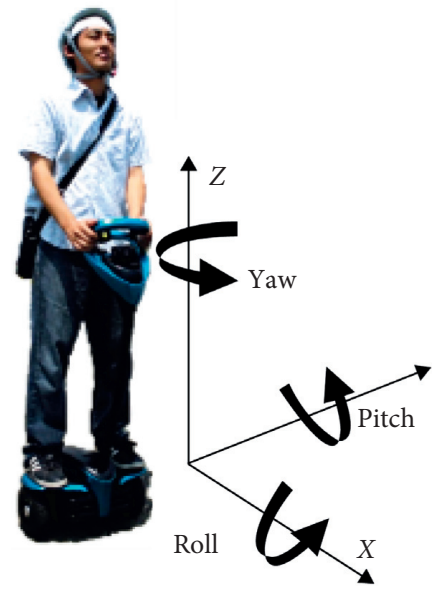

(c)

FIgURE 1: Winglet equipped with mobile sensors. The image shows the $X, Y$, and $Z$ and roll, pitch, and yaw coordinate systems.

TABLE 1: Winglet specifications.

\begin{tabular}{lc}
\hline Property & Specification \\
\hline Length & $265(\mathrm{~mm})$ \\
Width & $464(\mathrm{~mm})$ \\
Height & $1130(\mathrm{~mm})$ \\
Tire diameter & $150(\mathrm{~mm})$ \\
Max. velocity & $6(\mathrm{~km} / \mathrm{h})$ \\
Weight & $12.3(\mathrm{~kg})$ \\
Battery & Lithium ion \\
Distance (km per charge) & $\sim 4(\mathrm{~km})$ \\
Turning radius & $0(\mathrm{~m})$ \\
Climbing distance & $20(\mathrm{~mm})$ \\
\hline
\end{tabular}

\section{Experimental Method}

This section describes the various scenarios and experimental conditions, as well as the contents of the questionnaires given to the subjects before and after the experimental trials. Three scenarios were tested during the experiments, each with different subjects and environmental conditions.

3.1. Experimental Location. Experiments using standingtype mobility devices in public areas are prohibited by Japanese law. Therefore, any experiment conducted in such areas must be conducted under strict conditions; however, very little insight can be gained from these experiments, and they prevent natural interactions of people from being investigated.

In 2012, the Cabinet Office in Japan decided to construct the Tsukuba Designated Zone. As of December 2016, when experimental trials commenced, seven private companies, including the Toyota Motor Corporation and Aisin Seiki Corporation, several nonprofit organizations, including the National Institute of Advanced Industrial Science and Technology (AIST), and three universities have contributed to the construction of this zone.
3.2. Experimental Scenarios. To investigate the research questions, we designed three experimental scenarios, each involving different route characteristics. Table 2 provides a summary of each scenario; here, "number of times" denotes the total number of experiments. When one subject completes the route, the number increases by one. Thus, some subjects tried the course two or more times.

3.2.1. Scenario 1. The route for Scenario 1 began at the AIST and continued to Tsukuba station, the nearest train station [34]. Figure 2 demonstrates the route used in the experiment; it is largely flat but does include several slopes and pedestrian crossings. The route distance is approximately $3.6 \mathrm{~km}$.

The AIST provides a complimentary shuttle-bus service for its employees. It takes approximately $30 \mathrm{~min}$ to reach Tsukuba station from the AIST because the bus stops at several intermediary locations. These buses are an inefficient mode of transport because they operate approximately once every $40 \mathrm{~min}$. Therefore, this route was chosen as an experimental scenario, and the subjects used the Winglet instead of the bus. Table 2 presents the number and ages of participants in Scenario 1 trials.

This route was the longest of the three. Thus, the course was divided into five sections (Figure 2), to analyze the effects of specific road characteristics and conditions on vehicle operation. These sections are as follows:

(A) From AIST Central 2 to the pedestrian crossing in the AIST complex

(B) From the pedestrian crossing in the AIST complex to Matsubokkuri Park

(C) From Matsubokkuri Park to Ninomiya Park

(D) From Ninomiya Park to the pedestrian crossing near the Tsukuba International Congress Center

(E) From the pedestrian crossing near the Tsukuba International Congress Center to Tsukuba station 
TABLE 2: Features of each scenario.

\begin{tabular}{lccc}
\hline & Scenario 1 & Scenario 2 & Scenario 3 \\
\hline Route & AIST to Tsukuba St & City office to Kenkyugakuen St & Shopping mall to Kenkyugakuen St \\
Subject (age: average and range) & AIST staff (46.6 and 31-56) 20 & Office staff $(36.6$ and 26-57) 10 & Mall staff (47.5 and 25-75) 10 \\
Number of subjects & $3.6 \mathrm{~km}$ & $0.7 \mathrm{~km}$ & $0.6 \mathrm{~km}$ \\
$\begin{array}{l}\text { Distance } \\
\text { Number of times }\end{array}$ & 53 & 49 & 23 \\
Flatness & Flat and sloping sections & Flat & Flat \\
\hline
\end{tabular}

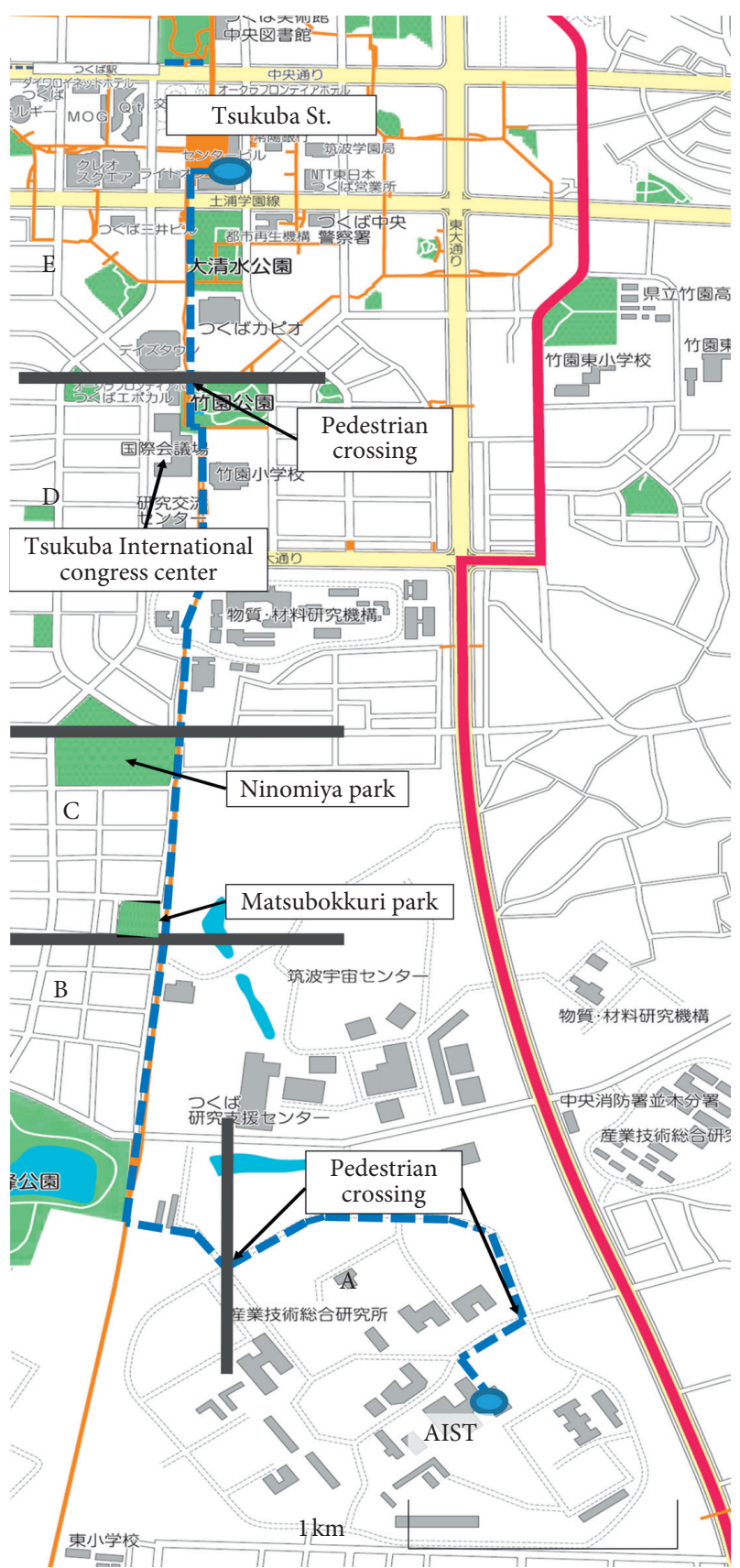

Figure 2: Experimental route for Scenario 1 (dashed blue line: route; blue circles: start and end points; gray lines: borders between each of the five sections).
The features of each section are summarized in Table 3. Apart from Section A, all sections are public spaces.

3.2.2. Scenario 2. The route for Scenario 2 proceeds from the City Office to Kenkyugakuen station, as indicated by the dashed green line in Figure 3; it is approximately $0.7 \mathrm{~km}$ long and largely flat and features pedestrian crossings. Table 2 lists the number and ages of participants in Scenario 2 trials. Each subject operating the Winglet on this route was asked to perform the trial more than three times within a week. Expressed otherwise, the subject would use the Winglet as a commuter device, enabling us to more comprehensively evaluate the operation and acquire suggestions for improvements. The subjects were also asked to use the Winglet instead of their own vehicles.

3.2.3. Scenario 3. The route for Scenario 3 proceeds from the shopping mall to Kenkyugakuen station, as denoted by the dashed red lines in Figure 3; it is approximately $0.6 \mathrm{~km}$ long and largely flat and features several pedestrian crossings. Table 2 presents the number and ages of subjects completing the route for Scenario 3. These subjects were asked to use the Winglet during their break period.

3.3. Experimental Conditions. The number of trials completed by each subject differed between scenarios. To prevent bias, none of the subjects were associated with the Winglet or Toyota Motor Corporation. Each subject participated in the trials for one scenario only. Prior to the first trial, all subjects were trained to operate the Winglet. Moreover, the subjects participated in a seminar that introduced the Winglet and explained the rules for operating it in an outdoor environment. All subjects voluntarily participated in the study after informed consent had been taken.

The subjects used the Winglets to travel from the starting location of the route to the corresponding destination. All trials were performed on the sidewalk, which is accessible to both cyclists and pedestrians. All routes involved several pedestrian crossings. The use of public areas is considered significant in evaluating the experimental results because it more accurately reflects the reallife operation of personal mobility vehicle than results obtained from restricted areas. No testing was performed in rainy or dark conditions, to prevent adding the further 
TABLE 3: Features of each section.

\begin{tabular}{lccc}
\hline Section & $\begin{array}{c}\text { Distance } \\
\text { (approx. })\end{array}$ & Pedestrian density & Features \\
\hline A & $1.1 \mathrm{~km}$ & Lowest & $\begin{array}{c}\text { Asphalt road and a wide course } \\
\text { Eleven bump spots at road crossings }\end{array}$ \\
\hline $\mathrm{B}$ & $0.8 \mathrm{~km}$ & Lower than areas C and E and comparable with area D & $\begin{array}{c}\text { No bump spots and a wide course } \\
\text { Surface paved with stones and asphalt }\end{array}$ \\
\hline $\mathrm{C}$ & $0.4 \mathrm{~km}$ & Comparable with area E & $\begin{array}{c}\text { Asphalt road and no rough surfaces as road crossings } \\
\text { Narrow course, approx. 3 m wide } \\
\text { Pedestrians share sidewalk with cyclists }\end{array}$ \\
\hline $\mathrm{D}$ & $0.9 \mathrm{~km}$ & Lower than areas C and E and comparable with area B & $\begin{array}{c}\text { No bump spots, wide course, and asphalt road } \\
\text { Pedestrians must share sidewalk with bicycles }\end{array}$ \\
\hline $\mathrm{E}$ & $0.6 \mathrm{~km}$ & Highest & No bump spots, wide course, and asphalt road \\
\hline
\end{tabular}

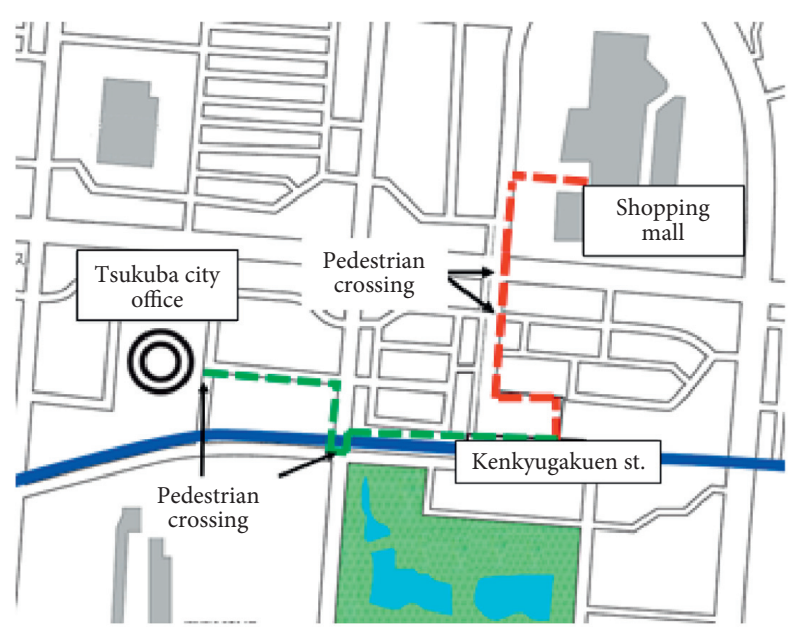

FIgURE 3: Experimental routes for Scenarios 2 and 3 (dashed green line: route for Scenario 2; dashed red line: route for Scenario 3).

analysis dimension of weather when evaluating the effects of human factors and safety. During each trial, one person followed behind the Winglet user in case of emergency. A research ethics committee meeting was conducted in AIST before performing the experiments; the committee members consisted of specialists from academia and industry who had no financial interest in AIST; they granted us permission to conduct our experiments.

3.4. Questionnaires. Each subject was requested to complete a questionnaire before and after participating in the experiments. Initially, the number of postexperiment questions was large. Thus, we chose questions whose answers did not relate to the experiment and asked these before the trials because too large a questionnaire may lead to a loss of concentration. The pre-experiment questionnaire primarily concerned the participant habits and personal characteristics; it consisted of the following questions:

(I) What is your usual mode of transportation for this route?

(II) Do you have experience using this type of personal mobility vehicle?
(III) Do you regularly exercise?

Furthermore, the posttrial questionnaire consisted of the following questions:

(IV) Would you choose a Winglet again for the same route (if not, please provide reasons for your answer)?

(V) Do you think the route length was too long (if you do, please suggest an appropriate length)?

(VI) Was using a Winglet more comfortable than walking?

(VII) What are your opinions on the advantages and disadvantages of using a Winglet?

(VIII) What is your opinion of the $6 \mathrm{~km} / \mathrm{h}$ maximum speed?

(IX) Are there other conditions under which, or places where, you would like to use a Winglet?

(X) If you have any comments regarding this experiment, please let us know

When designing these questionnaires, we discussed their content with several developers who were planning to produce a new type of mobility device, and we referred to an earlier paper [29]. Furthermore, our research group had previously developed a smaller standing-type vehicle [30] and conducted several test rides and pre-experiment mobility trials thereof [27]. From these studies, we developed several hypotheses regarding human factors on the standingtype vehicle employed in the present study, and we finally decided upon the above questionnaire.

\section{Experimental Results and Discussion}

This experiment was performed in cooperation with the Tsukuba City Government. The total distance covered by the subjects was approximately $267 \mathrm{~km}$. The factors (e.g., social receptibility, safety, efficiency, and environmental protection (via substitution of high-emission vehicles with personal mobility vehicles)) were investigated and evaluated using the experimental results. The questionnaire results, safety analysis, and evaluation of individual differences between users (with respect to operation) are presented in the following sections. 
4.1. Questionnaire Results. This section presents the questionnaire and statistical analysis results.

Figure 4 and Table 4 present the results for Question IV; they show that the subjects held favorable opinions regarding the Winglet, with several expressing a desire to use it again in the future. The subjects who responded negatively to Question IV provided the following reasons for their answer:

(1) The commute took too long because of the low maximum speed

(2) I would like to use the Winglet alone without an accompanying person

(3) Travelling on uneven roads was uncomfortable

(4) I would like to avoid experiencing muscle fatigue in my feet

These comments indicate that the Winglet should be improved in terms of its comfortability and operation, which are highlighted as weak aspects of the device. With respect to the operation, we considered these types of devices to be generally designed for shared-rather than individual-use; thus, the design of the operation consider the anticipated users, environments, and usage conditions. Comfortability is an important design aspect of these devices, and to improve it, the influences of human factors-discussed later in this paper-should be considered.

Moreover, privacy was found to be an important factor when operating this type of mobility vehicle because several people stated a preference for using the Winglet alone, without an accompanying person.

Figure 5 and Table 4 present the results for Question V, which determined whether the route lengths for Scenarios 2 and 3 were felt to be appropriate; based on the subjects who responded in the affirmative, the average appropriate route distance for a Winglet was found to be approximately $2.6 \mathrm{~km}$.

Figure 6 and Table 4 show the results for Question VI. Approximately $60 \%$ of subjects reported that using the Winglet was more comfortable than walking, which indicates that using a Winglet may lead to a reduction in fatigue compared to walking, another potential benefit of the Winglet.

The positive responses to Question VII are as follows:

(1) I was able to enjoy great views because of the higher vantage point when riding the Winglet compared to walking

(2) I could communicate well because I felt comfortable during the experiment

(3) I can commute to my office without using my vehicle

(4) I can travel without sweating

(5) I was comfortable without the pitch movements involved in walking

(6) I can avoid getting my shoes dirty

Most subjects provided responses relating to the improved vantage point while riding the device; this was unexpected but may be a significant motivation for people to adopt a personal vehicle such as the Winglet. There were no negative responses for Question VII. One of the major reasons for negative responses has already been explained for Question IV.

Figure 7 and Table 4 depict the results for Question VIII. No subjects reported the maximum speed to be too fast; approximately $80 \%$ of the subjects who reported the maximum speed to be too slow expected it to exceed $10 \mathrm{~km} / \mathrm{h}$, with the average desired maximum speed being approximately $12 \mathrm{~km} / \mathrm{h}$. The maximum speed of the personal mobility vehicle is expected to be adjustable to suit user preferences.

Other possible uses for the Winglet, found from the results for Question IX, include the following:

(1) Travelling on sloping roads

(2) Travelling around a shopping mall

(3) Sightseeing

(4) Mobility assistance for users in poor physical condition

(5) Travelling to a restaurant during lunch break

(6) Patrolling (police, security, etc.)

Several subjects responded to Question X by saying that it was easy to avoid pedestrians with the Winglet because its footprint is similar to that of a pedestrian and it can be turned easily.

4.2. Safety Analysis Results from Video Recorder. The trip analysis of the test runs showed no accidents or near accident events that might have resulted in severe injuries. In comparison with the data available for other mobility devices (e.g., bicycles), the experimental data obtained in this experiment were not deemed sufficient to assess the safety of the device [35]. However, we extracted event scenes of interest from approximately $2500 \mathrm{~min}$ of Scenario 1 travelling data, to evaluate the social receptibility of the Winglet and analyze probable near-incident situations that may arise in the future. Only the travelling data from Scenario 1 were used in the safety analysis because this route was the longest and included five different types of environment. Tables 5 and 6 list the numbers of event types that occurred in Scenario 1. Events relating to bicycles were relatively frequent on this route because the subjects were required to share the sidewalk with cyclists in Sections C, D, and E (Table 5).

The events that occurred in each section are categorized and presented in Table 7 . Figure 8 shows several of the categorized events. We classified each event according to the actions of the subject (driver) and the reactions of the nearby third-party individual (pedestrian or cyclist). The results indicate that minimal interactions occurred between the Winglet riders and pedestrians or cyclists. An interaction was defined to have occurred when the recorded video showed that the Winglet rider performed intentional maneuvers to avoid cyclists or pedestrians, or vice versa. The percentages of rider and third-party reactions were approximately $3.68 \%$ and $2.83 \%$, respectively. The results also 


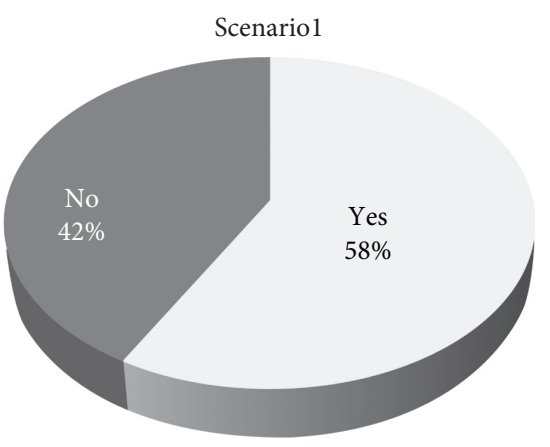

(a)

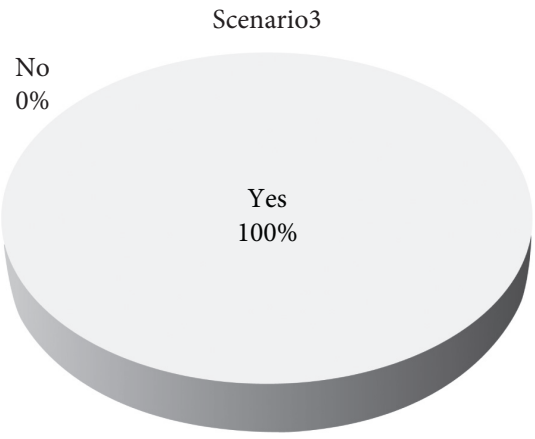

(c)

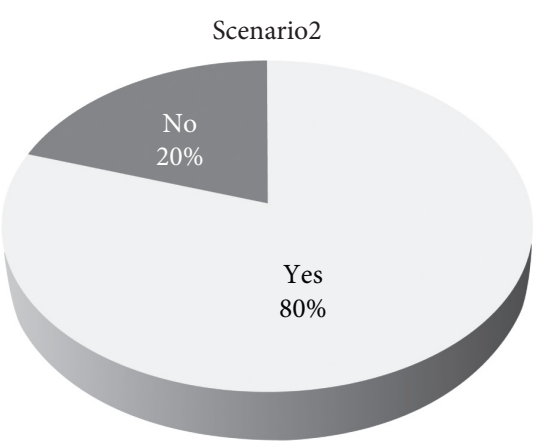

(b)

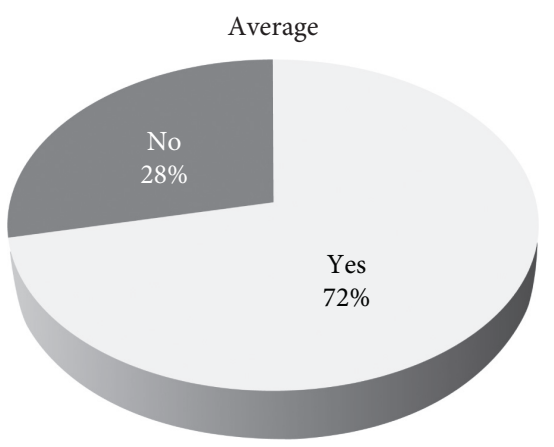

(d)

Figure 4: Results for question IV ("exercise" and "no exercise" indicate that the subject answered "yes" and "no" in questionnaire III, respectively).

TABLE 4: Results for questions IV, V, and VI with respect to exercise habits.

\begin{tabular}{lcccccc}
\hline & \multicolumn{3}{c}{ Exercise } & \multicolumn{3}{c}{ No exercise } \\
& Yes & No & Even & Yes & No & Even \\
\hline Results of question IV & $60 \%$ & $40 \%$ & - & $87 \%$ & $13 \%$ & - \\
Results of question V & $34 \%$ & $66 \%$ & - & $43 \%$ & $57 \%$ & - \\
Results of question VI & $73 \%$ & $4 \%$ & $23 \%$ & $50 \%$ & $7 \%$ & $43 \%$ \\
\hline
\end{tabular}

showed that the Winglet was well integrated into the pedestrian flow along the route, as indicated by the fact that the subjects and third-party individuals made few special avoidance maneuvers.

Consequently, the Winglets were found to have only minimal effects on the normal pedestrian flow. The reactions of the nearby pedestrians and cyclists that initially approached the Winglets suggested that they were interested in the device and wanted to see it more closely. Presumably, increased familiarity with Winglets will result in fewer thirdparty "approach" reactions in the future.

In terms of cyclist reactions, the results indicate that cyclists rarely needed to execute special maneuvers, and they had sufficient time to prepare when passing the Winglets. Although the cyclists travelled faster than Winglet, only two sudden-stop reactions were observed. It is assumed that cyclists can easily recognize a Winglet driver by their height difference, which makes them more visible when operating the device.

Regarding pedestrian reactions, the results indicate that pedestrians rarely performed particular avoidance maneuvers and that the Winglet riders occasionally maneuvered to avoid pedestrians. Though the maximum speed of the device was $6 \mathrm{~km} / \mathrm{h}$ (comparable to the speed of a pedestrian), the Winglet rider tended to maneuver to avoid a pedestrian before the pedestrian initiated avoidance maneuvering. The results for Question X in the previous section revealed that subjects found it easy to avoid pedestrians when driving the Winglet because the footprint of the Winglet is comparable to that of a pedestrian, and it is easily maneuverable.

4.3. Individual Differences. The relationships between the various factors identified from the questionnaire and the data analysis results were further analyzed using SPSS AMOS software to determine the factors that may affect the Winglet operation. Although the experimental conditions and subjects varied between the three scenarios, we were able to extract several relationships, as presented in Tables 7-9. Thereafter, we attempted to evaluate the statistical differences between each scenario by implementing Welch's $t$ test $[36,37]$; this uses the static parameter $t$, which is calculated as

$$
t=\frac{\overline{X_{1}}-\overline{X_{2}}}{\sqrt{S_{1}^{2} / n_{1}}+\sqrt{S_{2}^{2} / n_{2}}}
$$

where $\overline{X_{i}}$ is the average of group $i, s_{i}$ is the standard deviation in group $i$, and $n_{i}$ is the number of participants in group $i$; here, $i=1$ or 2 . The statistics obtained should follow a 


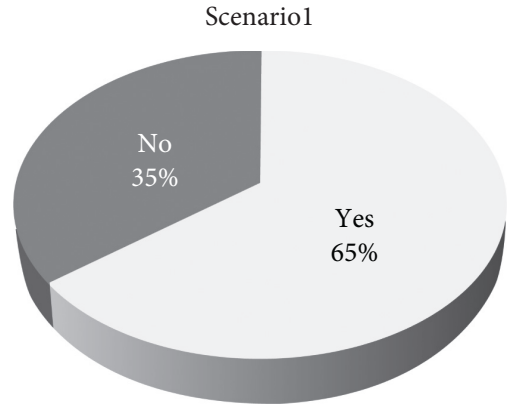

(a)

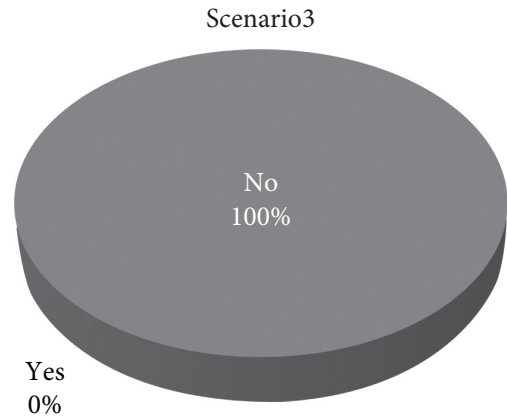

(c)

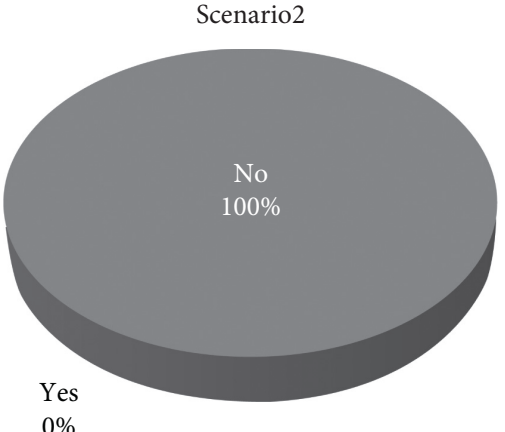

(b)

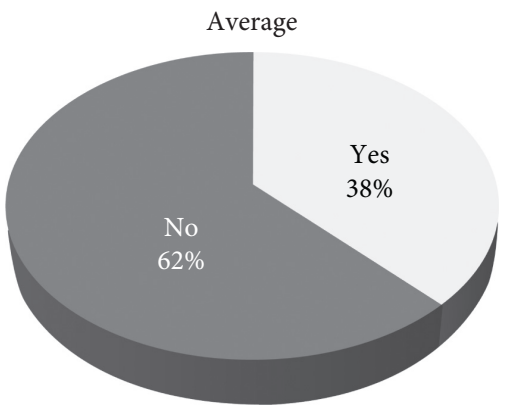

(d)

FIgURE 5: Results for question V.

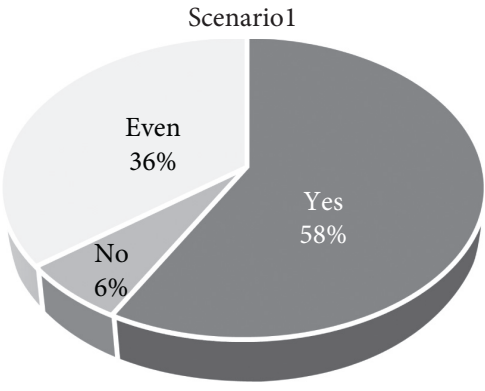

(a)

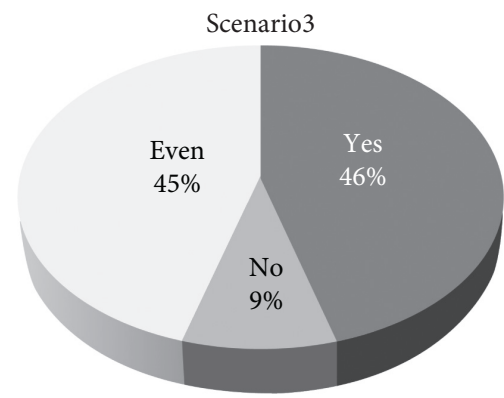

(c)

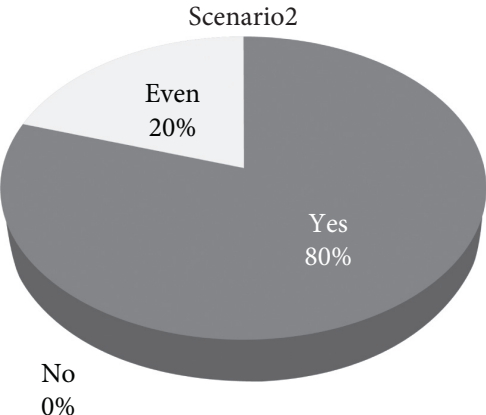

(b)

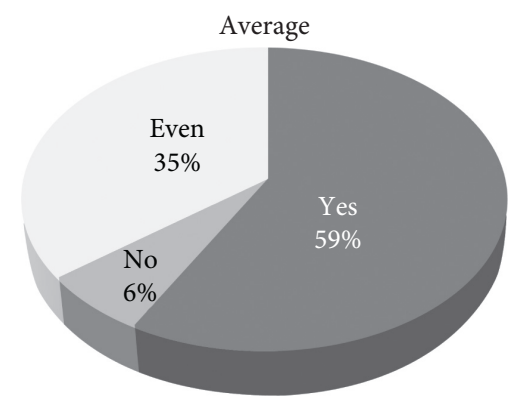

(d)

FIgURE 6: Results for question VI (“even” indicates neutral feelings).

standard normal distribution, which allows calculation of the $t$-test. The number of subjects (trial) was limited owing to budget restrictions (i.e., because public tests, using these devices are prohibited, performing them requires special government permission and extensive safety lectures to be given to subjects, and thereby making experiments 


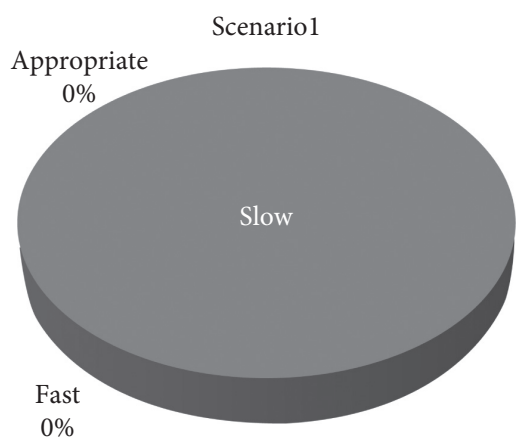

(a)

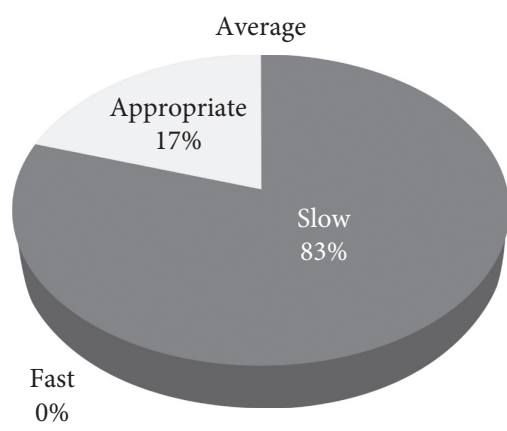

(d)

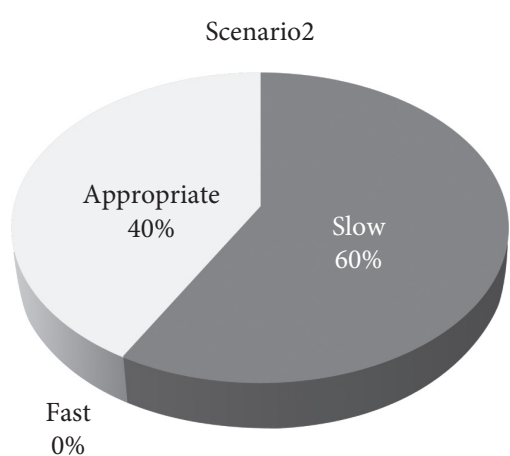

(b)

Average (exercise)

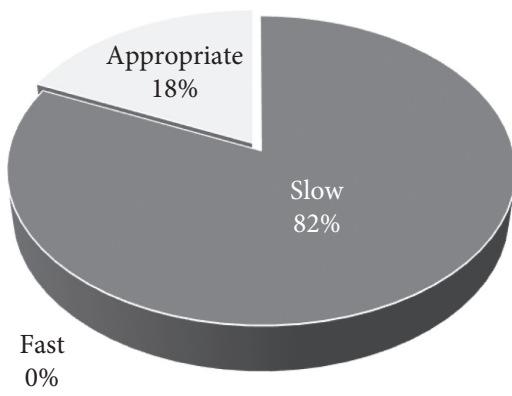

(e)

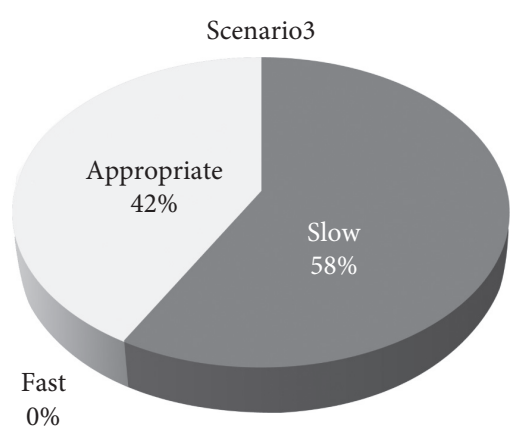

(c)

Average (no exercise)

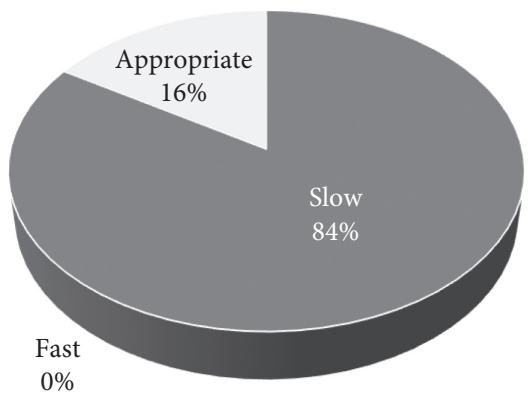

(f)

FIGURE 7: Results for question VIII.

TABLE 5: Scenario 1 events categorized according to area (objective: cyclists).

\begin{tabular}{|c|c|c|c|c|}
\hline Section & Event & Winglet driver's action & Objective's reaction & Number of times \\
\hline \multirow{4}{*}{ A } & Pass & Avoid & None & 3 \\
\hline & Pass & None & None & 15 \\
\hline & Bicycle overtakes & None & None & 3 \\
\hline & Cross & Stop & Avoid & 1 \\
\hline \multirow{8}{*}{ B } & \multirow{6}{*}{ Pass } & \multirow{2}{*}{ Avoid } & Stop & 1 \\
\hline & & & None & 5 \\
\hline & & \multirow{4}{*}{ None } & Avoid & 1 \\
\hline & & & Stop & 1 \\
\hline & & & Approach & 1 \\
\hline & & & None & 163 \\
\hline & \multirow{2}{*}{ Bicycle overtakes } & \multirow{2}{*}{ None } & Avoid & 1 \\
\hline & & & None & 40 \\
\hline \multirow{6}{*}{$\mathrm{C}$} & \multirow{4}{*}{ Pass } & \multirow{2}{*}{ Stop } & Decelerate & 1 \\
\hline & & & None & 1 \\
\hline & & \multirow{2}{*}{ None } & Avoid & 1 \\
\hline & & & None & 117 \\
\hline & \multirow{2}{*}{ Bicycle overtakes } & \multirow{2}{*}{ None } & Avoid & 1 \\
\hline & & & None & 36 \\
\hline \multirow{8}{*}{$\mathrm{D}$} & Winglet overtakes & None & None & 1 \\
\hline & \multirow{5}{*}{ Pass } & Avoid & None & 1 \\
\hline & & Decelerate & None & 2 \\
\hline & & \multirow{3}{*}{ None } & Avoid & 5 \\
\hline & & & Approach & 1 \\
\hline & & & None & 126 \\
\hline & \multirow{2}{*}{ Bicycle overtakes } & \multirow{2}{*}{ None } & Approach & 2 \\
\hline & & & None & 67 \\
\hline \multirow{6}{*}{$\mathrm{E}$} & \multirow{4}{*}{ Pass } & Stop & None & 1 \\
\hline & & Avoid & None & 1 \\
\hline & & \multirow{2}{*}{ None } & Avoid & 4 \\
\hline & & & None & 65 \\
\hline & Bicycle overtakes & None & None & 46 \\
\hline & Cross & None & None & 1 \\
\hline
\end{tabular}


TABLE 6: Scenario 1 events categorized according to area (objective: pedestrian).

\begin{tabular}{|c|c|c|c|c|}
\hline Section & Event & Winglet driver's action & Objective's reaction & Number of times \\
\hline \multirow{5}{*}{ A } & \multirow{3}{*}{ Pass } & Avoid & None & 2 \\
\hline & & \multirow{2}{*}{ None } & Avoid & 2 \\
\hline & & & None & 37 \\
\hline & \multirow{2}{*}{ Cross } & Decelerate & None & 2 \\
\hline & & None & None & 1 \\
\hline \multirow{8}{*}{ B } & \multirow{3}{*}{ Pass } & Avoid & None & 2 \\
\hline & & \multirow{2}{*}{ None } & Avoid & 4 \\
\hline & & & None & 60 \\
\hline & \multirow{3}{*}{ Winglet overtakes } & Avoid & None & 2 \\
\hline & & \multirow{2}{*}{ None } & Stop & 1 \\
\hline & & & None & 2 \\
\hline & Pedestrian overtakes & None & None & 2 \\
\hline & Cross & None & None & 1 \\
\hline \multirow{4}{*}{$\mathrm{C}$} & \multirow{3}{*}{ Pass } & Avoid & None & 3 \\
\hline & & Stop & None & 1 \\
\hline & & None & None & 15 \\
\hline & Winglet overtakes & None & None & 1 \\
\hline \multirow{5}{*}{$\mathrm{D}$} & \multirow{2}{*}{ Pass } & Avoid & None & 2 \\
\hline & & None & None & 66 \\
\hline & \multirow{2}{*}{ Pedestrian overtakes } & \multirow{2}{*}{ None } & Approach & 1 \\
\hline & & & None & 5 \\
\hline & Winglet overtakes & None & None & 3 \\
\hline \multirow{7}{*}{$\mathrm{E}$} & \multirow{4}{*}{ Pass } & Avoid & None & 5 \\
\hline & & \multirow{3}{*}{ None } & Avoid & 2 \\
\hline & & & Approach & 1 \\
\hline & & & None & 93 \\
\hline & Pedestrian overtakes & None & None & 4 \\
\hline & \multirow{2}{*}{ Winglet overtakes } & Avoid & None & 2 \\
\hline & & None & None & 23 \\
\hline
\end{tabular}

TABLE 7: Number of events according to section in scenario 1.

\begin{tabular}{lccc}
\hline Section & Bicycle & $\begin{array}{c}\text { Objective } \\
\text { Pedestrian }\end{array}$ & Sum \\
\hline A & 22 & 44 & 66 \\
B & 213 & 74 & 287 \\
C & 157 & 20 & 177 \\
D & 205 & 77 & 282 \\
E & 119 & 130 & 249 \\
Sum & 716 & 345 & 1061 \\
\hline
\end{tabular}

expensive). Thus, the number of trials was small; in Welch's $t$-test, if the number of subjects is small, the number of degrees of freedom is low, and the $t$ value required to prove significance is considerably high.

The leftmost columns in Tables 8-10 present the parameters of the travelling data for one trial. The top horizontal row shows the related human factors as determined by the questionnaire results (e.g., age and gender). A 95\% confidence level setting revealed the following statistical differences:

(1) The standard deviations of acceleration in the $X, Y$, and $Z$ directions, as well as the pitch, roll, and yaw rates, in Columns $1-4$ in Table 8
(2) The average and standard deviation of velocity and the standard deviation of acceleration in $Y$ in Columns $2-4$ in Table 9

(3) The standard deviation of acceleration and roll axis in Columns 3-4 in Table 10

The subjects tended to rate their experience of the Winglet more positively than that of their usual mode of transportation. Of particular interest are the differences in the following seven items with respect to the subjects from Scenario 1 who typically used a bicycle and those who typically drove a private vehicle: the standard deviations of acceleration in the $X, Y$, and $Z$ directions; the standard deviations of the pitch, roll, and yaw rates; and the buzzer duration ratio.

This implies that the acceleration was important for user acceptance. Therefore, in this study, we included the acceleration data for evaluation. The Winglet buzzer beeps when the vehicle is speeding. These seven items are positive, which means that these subjects operated the Winglet without being affected by sidewalk disturbances, by absorbing the impact thereof. This result indicates that subjects who typically use a bicycle are adept at avoiding and absorbing the impacts of small holes and bumps, thereby reducing their acceleration values in all directions as well as their pitch, roll, and yaw rates. 


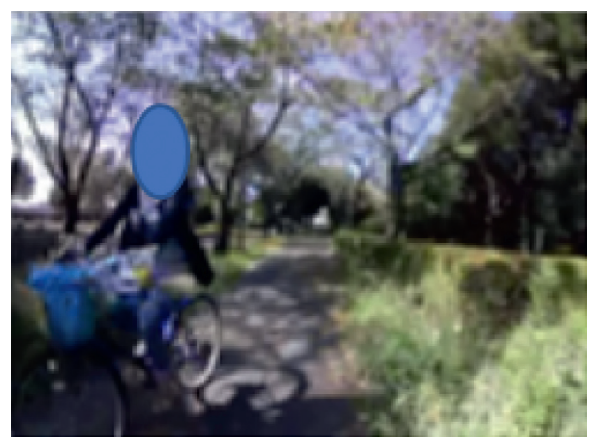

(a)

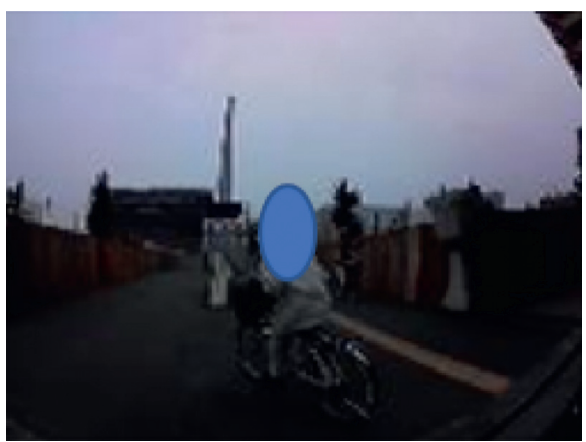

(c)

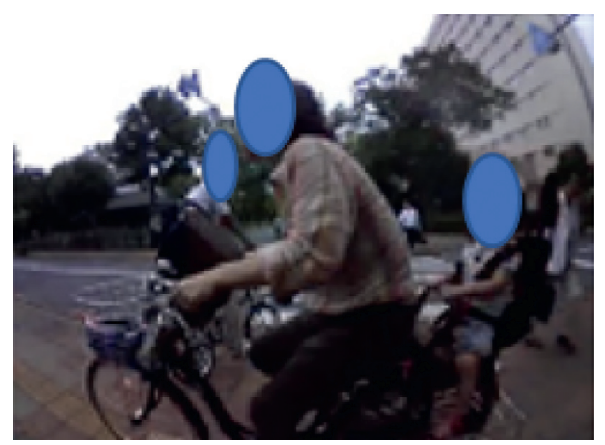

(b)

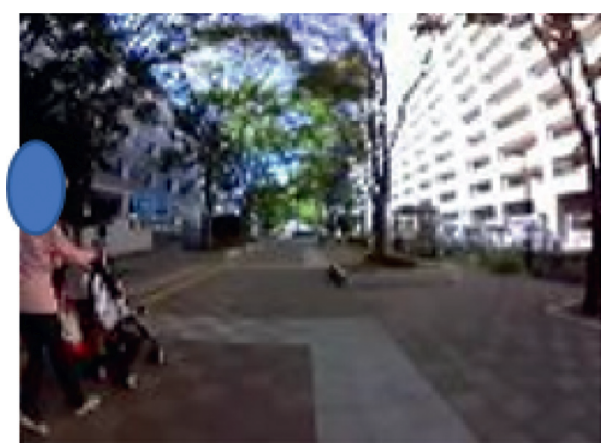

(d)

FIGURE 8: Scenes of the categorized events of scenario 1 (top left: section $=\mathrm{D}$, objective $=$ avoid, winglet $=$ none; top right: section $=\mathrm{E}$, event $=$ cross, and winglet $=$ none; bottom left: section $=\mathrm{E}$, event $=$ bicycle overtakes, winglet $=$ none; bottom right: section $=\mathrm{E}$, event $=$ pass, and winglet $=$ stop) (faces of persons unrelated to the study have been covered to protect their privacy).

TABLE 8: $t$-test results for various differences in scenario 1 (avg: average; SD: standard deviation; accel: acceleration; ans: answer; Q: question).

\begin{tabular}{lcccc}
\hline & $\begin{array}{c}\text { between exercise and } \\
\text { no exercise }\end{array}$ & $\begin{array}{c}\text { between ans: yes } \\
\text { and ans: no in Q V }\end{array}$ & $\begin{array}{c}\text { between ans: yes and ans: } \\
\text { no in Q VI }\end{array}$ & $\begin{array}{c}\text { between ans: vehicle and ans: } \\
\text { bicycle in Q I }\end{array}$ \\
\hline Avg. velocity & -0.281 & -0.520 & 0.241 & 0.947 \\
SD of velocity & 0.924 & 0.411 & 0.108 & 1.360 \\
SD of accel. in X & -0.208 & 0.162 & 0.935 & 2.304 \\
SD of accel. in Y & -0.509 & -0.113 & 1.735 & 3.803 \\
SD of accel. in Z & 0.019 & 0.189 & -1.398 & 2.190 \\
SD of pitch rate & 0.255 & 0.925 & 0.268 & 3.662 \\
SD of roll rate & -0.454 & 0.201 & 0.216 & 2.912 \\
SD of yaw rate & 1.329 & -0.170 & 0.760 & 3.599 \\
Buzzer duration ratio & -0.027 & 0.588 & 0.739 & 2.993 \\
\hline
\end{tabular}

TABLE 9: $t$-test results for effects of human factors in scenario 2 (avg.: average, SD: standard deviation, accel.: acceleration, ans: answer, Q: question).

\begin{tabular}{lcccc}
\hline & between exercise and no exercise & between female and male & $\begin{array}{c}\text { between first time } \\
\text { and third time }\end{array}$ & $\begin{array}{c}\text { between ans: yes and ans: } \\
\text { no in Q V }\end{array}$ \\
\hline Avg. velocity & -1.636 & 0.110 & -0.538 & 2.094 \\
SD of velocity & 0.196 & 1.067 & 0.334 & -2.603 \\
SD of accel. in X & 1.584 & -0.295 & -1.270 & -0.416 \\
SD of accel. in Y & 1.748 & 1.422 & -1.561 & 2.456 \\
SD of accel. in Z & -0.615 & -0.700 & -0.765 & -0.660 \\
SD of pitch rate & 0.765 & -1.038 & -0.435 & -0.391 \\
SD of roll rate & -0.253 & -1.580 & 0.081 & -0.771 \\
SD of yaw rate & 0.805 & -1.696 & 1.146 & -0.938 \\
Buzzer duration ratio & 0.542 & 0.503 & -1.999 & -0.575 \\
\hline
\end{tabular}


TABLE 10: $t$-test results for effects of human factors in scenario 3 (avg.: average, SD: standard deviation, accel.: acceleration, ans: answer, Q: question).

\begin{tabular}{lcccc}
\hline & between exercise and no exercise & between female and male & $\begin{array}{c}\text { between first time } \\
\text { and third time }\end{array}$ & $\begin{array}{c}\text { between ans: yes } \\
\text { and ans: no in Q I }\end{array}$ \\
\hline Avg. velocity & -1.636 & 0.110 & -0.538 & 2.094 \\
SD of velocity & 0.196 & 1.067 & 0.334 & -2.603 \\
SD of accel. in $X$ & 1.584 & -0.295 & -1.270 & -0.416 \\
SD of accel. in $Y$ & 1.748 & 1.422 & -1.561 & -0.456 \\
SD of accel. in $Z$ & -0.615 & -0.700 & -0.765 & -0.660 \\
SD of pitch rate & 0.765 & -1.038 & -0.435 & -0.391 \\
SD of roll rate & -0.253 & -1.580 & 1.146 & -0.771 \\
SD of yaw rate & 0.805 & -1.696 & -1.999 & -0.938 \\
Buzzer duration ratio & 0.542 & 0.503 & -0.575 \\
\hline
\end{tabular}

With a $95 \%$ confidence level, a reduced statistical difference was found when considering the influences of age, gender, and exercise frequency on the parameters of travelling data. Moreover, all elderly riders answered YES to Question IV. In Table 9, a smaller statistical difference was observed between the first and third trials, suggesting that all subjects could easily become accustomed to operating and manipulating a Winglet. Therefore, Winglet operation was concluded to be feasible for all types of people, regardless of the differences in factors (e.g., age, gender, and exercise frequency).

When evaluating the effects of environmental conditions on the travelling data parameters in Scenario 1, the average driving speed in Section B was found to be $5 \%$ lower than that observed in the other sections. The riders may have driven more slowly in this section because the course was narrower than the others. Moreover, at a 95\% confidence level, a reduced statistical difference in the average driving speed was found to be consistent among all the sections in Scenario 1.

\section{Discussion with Three Analyses}

Based on the responses in Section 4.1, we derived the following conclusions regarding the use of the Winglet:

(1) The device should be utilized for short journeys owing to its size and velocity

(2) It can serve multiple purposes, including commuting and sightseeing

(3) It would be suitable as a private transportation device for reaching nearby amenities on a daily basis

(4) It can reduce the fatigue of riders, especially when travelling uphill or downhill on sloping roads

Accordingly, we derived the following conclusions:

(1) As observed, it is unlikely that Winglets will affect cyclists in areas of mixed traffic because of the high visibility of the Winglet rider

(2) Winglet riders can share pedestrian roads with pedestrians because the device occupies a small area and can maneuver as pedestrians do

Based on the results of the individual analyses, it is concluded that exercise habits affect the use of these standing-type vehicles. Meanwhile, the following factors were not found to affect their use:

(1) Familiarity of using the Winglet (related to Questions $\mathrm{V}$ and VI and experience)

(2) Age and gender

These analyses indicate that the Winglet personal mobility device has a favorable social receptibility and was safe to operate on sidewalks, irrespective of the gender or age of the driver. In addition, the analysis results reveal that several factors should be considered when further developing such vehicles:

(1) Because these devices are for shared use, the operation instructions, user expectations, and usage environment must be clear

(2) Based on the operation, the velocity should be set by considering the average operating time or usage distance because large journey times or distances are not acceptable

(3) To improve the public reception of these devices, the opinions of those who rarely exercise and/or use a bicycle should be positively accepted

(4) In the design, the acceleration of Y should primarily be considered, whilst keeping the vehicle size compact

\section{Conclusions}

We conducted public experiments on a personal mobility device to assess its viability as a solution to the last-/first-mile problem. Operational evaluations under real-world conditions are necessary to evaluate the feasibility of standing-type personal vehicles as personal mobility devices. This study was conducted as part of a pilot program to test the vehicle; the results are expected to yield useful information for evaluating its social receptibility, safety, acceptability, and efficiency. We hope to use this information to solve the last-/ first-mile problem and thereby provide an effective solution to urban congestion and its associated risks.

Three experimental scenarios were tested. Each was implemented on a different route with different subjects. We obtained and evaluated the experimental data, which included measurements of the average velocity; the standard 
deviations of the motion information in $X, Y$, and $Z$ directions; the roll, pitch, and yaw rates; and questionnaire results related to the speed, safety, stability, and comfort of the standing-type vehicle.

No accidents occurred during the trials. To conclude, the Winglet had a minimal effect on the flow of pedestrians and cyclists. In terms of human factors, the factors of age, gender, and familiarity with and opinions of Winglet use were determined-by implementing Welch's $t$-test with a 95\% confidence level-to not be significant. However, the frequency of exercise affected the Winglet riding experience. These results demonstrate that the Winglet had a favorable social receptibility when operated on sidewalks, irrespective of the gender or age of the driver. However, large quantities of experimental data describing natural interactions with bicycles and pedestrians are required to statistically verify the safety of the Winglet. Therefore, a future study will conduct further experimental trials with more vehicles and subjects. In addition, this type of personal mobility vehicle could be improved by offering the ability to adjust the maximum speed according to the environmental conditions and ability of the user to maintain stability; such a feature will improve rider comfort and optimize the device operation, thereby increasing its potential as an urban transport solution.

\section{Data Availability}

No data were used to support this study.

\section{Conflicts of Interest}

The authors declare that they have no conflicts of interest.

\section{Acknowledgments}

This research was supported by the New Energy and Industrial Technology Development Organization.

\section{References}

[1] US Department of Transportation, Beyond Traffic-Trends and Choices, US Department of Transportation, Washington, DC, USA, 2015.

[2] European Commission, https://ec.europa.eu/transport/themes_ en.

[3] M. Li, J. Hallam, L. Pryor, S. Chan, and K. Chong, "A cooperative intelligent system for urban traffic problems," in Proceedings of the IEEE International Symposium on Intelligent Control, Dearborn, MI, USA, September 1996.

[4] M. Seredynski and F. Viti, "A survey of cooperative its for next generation public transport systems," in Proceedings of 19th International Conference on Intelligent Transportation Systems, pp. 1229-1234, Rio de Janeiro, Brazil, November 2016.

[5] S. Tsugawa, "Results and issues of an automated truck platoon within the energy ITS project," in Proceedings of IEEE Intelligent Vehicles Symposium, pp. 642-647, Dearborn, MI, USA, June 2014.

[6] S. Shladover, "Cooperative (rather than autonomous) vehiclehighway automation systems," IEEE Intelligent Transportation Systems Magazine, vol. 1, pp. 10-19, 2009.
[7] X. Fu, M. Vernier, A. Kurt, K. Redmill, and U. Ozguner, "Smooth: improved short-distance mobility for a smarter city," in Proceedings of the 2nd International Workshop on Science of Smart City Operations and Platforms Engineering, Pittsburgh, PA, USA, April 2017.

[8] B. Flamm and C. Rivasplata, Perceptions of Bicycle-Friendly Policy Impacts on Accessibility to Transit Services: The First and Last Mile Bridge, Mineta Transportation Institute Publications, San Jose, CA, USA, 2014.

[9] European Commission, Design Features for Support Programs for Investments in Last-Mile Infrastructure, European Commission, Brussels, Belgium, 2016.

[10] J. D. Kim, H. J. Lee, and I. S. Suh, "Strategic planning on electric PMV for sustainable mobility," in Proceedings of $93 \mathrm{rd}$ Transportation Research Board, Washington, DC, USA, January 2014.

[11] V. Renaudin, A. Dommes, and M. Guilbot, "Engineering, human, and legal challenges of navigation systems for personal mobility," IEEE Transactions on Intelligent Transportation Systems, vol. 18, no. 1, pp. 171-194, 2017.

[12] A. Kornhauser, S. Vin, S. McDonald, N. Serulle, and S. Young, "Deliberations public transportation and shared mobility," in Proceedings of 93rd Transportation Research Board, Washington, DC, USA, January 2014.

[13] T. Q. Pham, C. Nakagawa, A. Shintani, and T. Ito, "Evaluation of the effects of a personal mobility vehicle on multiple pedestrians using personal space," IEEE Transactions on Intelligent Transportation Systems, vol. 16, no. 4, pp. 2028-2037, 2015.

[14] Cabinet Office Japan, Annual Report on the Aging Society FY 2019, Cabinet Office, Chiyoda, Japan, 2019.

[15] X. Chen, Z. Liu, and G. Currie, "Optimizing location and capacity of rail-based park-and-ride sites to increase public transport usage," Transportation Planning and Technology, vol. 39, no. 5, pp. 507-526, 2016.

[16] K. Pavkova, G. Currie, A. Delbosc, and M. Sarvi, "A new approach to exploring the operational performance of public transport links, the case of Melbourne, Australia," in Proceedings of the Australasian Transport Research Forum Proceedings, Sydney, Australia, October 2015.

[17] Z. J. Chong, B. Qin, T. Bandyopadhyay et al., "Autonomous personal vehicle for the first-and last-mile transportation services," in Proceedings of the IEEE 5th International Conference on Cybernetics and Intelligent Systems, Qingdao, China, September, 2011.

[18] A. Scheltes and G. Correia, "Exploring the use of automated vehicles as last mile connection of train trips through an agent-based simulation model: an application to Delft, Netherlands," International Journal of Transportation Science and Technology, vol. 6, no. 1, pp. 28-41, 2017.

[19] K. Tan, K. Htet, and A. Narayanan, "Mitigation of vehicle distribution in an EV sharing scheme for last mile transportation," IEEE Transactions on Intelligent Transportation Systems, vol. 16, no. 5, pp. 2631-2641, 2015.

[20] C. Pakdeewanich, R. Tiyarattanacha, and O. Anantavrasilp, "Locally designed campus smart bike sharing system: lessons learned and design optimization for Thailand," in Proceedings of the IEEE 7th International Conference on Industrial Engineering and Applications (ICIEA), pp. 721-725, Bangkok, Thailand, April, 2020.

[21] L. Barreto, A. Amaral, and S. Baltazar, "Urban mobility digitalization: towards mobility as a service (MaaS)," in Proceedings of the International Conference on Intelligent Systems, pp. 850-855, Funchal, Portugal, 2018. 
[22] P. Lavallee, Pilot Project for Evaluating Motorized Personal Transportation Devices: Segways and Electric Scooters, Centre for Electric Vehicle Experimentation, Quebec, Canada, 2004.

[23] ACT Government, Segway Review Report: A Review of Segway Use in the Australian Capital Territory, Technical Report, ACT Government, Canberra, Australia, 2012.

[24] M. Ciężkowski and E. Pawłuszewicz, "Determination of interactions between two-wheeled self-balancing vehicle and its rider," in Proceedings of 20th International Conference on Methods and Models in Automation and Robotics, pp. 851855, Miedzyzdroje, Poland, August 2015.

[25] A. Smirnov, A. Kashevnik, I. Lashkov, N. Hashimoto, and A. Boyali, "Smartphone-based two-wheeled self-balancing vehicles rider assistant," in Proceedings of FRUCT, Yaroslavl, Russia, April 2015.

[26] M. Alqudah, M. Abdelfattah, I. Boiko, and K. Alhammadi, "Dynamic modeling and control design for a self-balancing two-wheel chair," in Proceedings of the 5th International Conference on Electronic Devices, Systems and Applications, Ras Al Khaimah, UAE, December 2016.

[27] N. Hashimoto, K. Tomita, A. Boyli et al., "Operational evaluation of new transportation method for smart city -use of personal mobility vehicles under three different scenarios," in Proceedings of SMART, Brussels, Belgium, June 2015.

[28] T. Winglet, 2020, http://newsroom.toyota.co.jp/en/detail/11463035/.

[29] R. Ando and A. Li, “"An analysis on users” evaluation for selfbalancing two-wheeled personal mobility vehicles'," in Proceedings of 15th International Conference on Intelligent Transpiration Systems, Anchorage, AK, USA, September 2012.

[30] N. Hashimoto, Y. Takinami, and O. Matsumoto, "An experimental study on vehicle behavior to wheelchairs and standing-type vehicles at intersection," in Proceedings of the 13th International Conference on ITS Telecommunications, Tampere, Finland, December 2013.

[31] J. Miller and D. Howell, "The EV everywhere grand challenge," in Proceedings of the World Electric Vehicle Symposium and Exhibition, Barcelona, Spain, November 2013.

[32] Robot special zone demonstration experiment promotion council, http://council.rt-tsukuba.jp, 2020.

[33] A. Castaings, W. Lhomme, R. Trigui, and A. Bouscayrol, "Energy management in EVs using battery and supercapacitors: algebraic loop issue," in proceedings of the 2014 16th European Conference on Power Electronics and Applications, Lappeenranta, Finland, August, 2014.

[34] AIST, http://www.aist.go.jp/index_en.html, 2020.

[35] ITF Research Reports, "Cycling, health and safety (ITF, 2013)," ITF Research Reports, OECD Publishing, Paris, France, 2013.

[36] B. L. Welch, “The generalization of student's problem when several different population variances are involved," Biometrika, vol. 34, no. 1, pp. 28-35, 1947.

[37] L. Zhiying, Q. Zhao, and Y. Le, “A segmentation method for crossing ambiguity string based on mutual information and t-test difference," in Proceedings of Conference on Information, Computing and Telecommunication, Bengaluru, India, 2009. 